\title{
The PDGF signaling pathway controls multiple steroid-producing lineages
}

\author{
Jennifer Schmahl, ${ }^{1}$ Kamran Rizzolo, ${ }^{2}$ and Philippe Soriano ${ }^{3,4}$ \\ Program in Developmental Biology, Division of Basic Sciences, Fred Hutchinson Cancer Research Center, Seattle, \\ Wshington 98109, USA
}

\begin{abstract}
The platelet-derived growth factor (PDGF) signaling pathway regulates numerous lineages of mesenchymal cell origin during development and in the adult. The transcriptional targets of this pathway have been shown to be required in several PDGF-dependent processes, but the roles of these targets in specific tissues is just beginning to be identified. In this study, we show that five different PDGF target genes are essential for male and/or female fertility. Mutations in each of these five different genes lead to defects in the steroid-producing cells in the testis and/or ovary and altered hormone production, suggesting that the PDGF pathway controls steroidogenesis through these genes in both sexes. Furthermore, conditional mutations of both PDGF receptors revealed a requirement in steroid-producing cells in multiple organs, including the testis, ovary, and adrenal cortex. Therefore, PDGF signaling may constitute a common mechanism in the control of multiple steroidogenic lineages.
\end{abstract}

[Keywords: PDGF; testis; ovary; steroid hormone; Leydig cell; theca cell]

Supplemental material is available at http://www.genesdev.org.

Received August 2, 2008; revised version accepted October 8, 2008.

Steroidogenesis and the development of the steroid-producing cells in the gonads is a tightly controlled process in both sexes, requiring regulation at many stages of development through endocrine, autocrine, and paracrine mechanisms. Defects in these processes lead to infertility, malformation of the reproductive tracts, and abnormal secondary sexual characteristics. In males, low testosterone production leads to abnormalities in spermatogenesis, undescended testes, ambiguous genitalia, and infertility (Habert et al. 2001). In females, the production of estrogen and progesterone is essential for ovulation and the maintenance of pregnancy (Fisher et al. 1998; Toda et al. 2001). Altered levels of steroid hormones are known to be associated with many of the common types of infertility in both men and women, such as hypogonadism and Polycystic Ovary Syndrome (PCOS), yet many of the mechanisms that control steroidogenic cell development and hormone production are not well understood.

In the gonads, steroid hormones are synthesized by specialized endocrine cells: the Leydig cells in the testis (Habert et al. 2001) and theca cells in the ovary (Magoffin

Present addresses: ${ }^{1}$ Regeneron Pharmaceuticals, 777 Old Saw Mill River Road, Tarrytown, NY 10591, USA; ${ }^{2}$ Broad Institute, 7 Cambridge Center, Cambridge, MA 02142, USA: ${ }^{3}$ Department of Developmental and Regenerative Biology, Mt. Sinai School of Medicine, 1 Gustave L. Levy Place, New York, NY 10029, USA.

${ }^{4}$ Corresponding author.

E-MAIL philippe.soriano@mssm.edu; FAX (212) 860-9279.

Article is online at http://www.genesdev.org/cgi/doi/10.1101/gad.1723908.
2005). In the testis, Leydig cells have at least two clearly defined waves of development, as fetal and adult Leydig cells. Fetal Leydig cells appear very early after sex determination, by embryonic day 12.5 (E12.5) in the mouse, and testosterone production from these cells is necessary for the masculinization of the fetus. Postnatally, fetal Leydig cells are replaced by adult Leydig cells, which are required for the progression and maintenance of spermatogenesis. In the ovary, the production of steroid hormones requires cooperation between two cell types, the theca and granulosa cells (Magoffin 2005). Theca cells are steroidogenic, as they initiate steroid synthesis by importing cholesterol to the mitochondrial membrane and synthesize steroid hormones de novo. However, theca cells produce largely androgens, which are converted into estrogen by granulosa cells. In the absence of estrogen production, follicles arrest at antral stages (Fisher et al. 1998; Toda et al. 2001), indicating that estrogen synthesis is not necessary for early follicle development, but is essential for ovulation and fertility.

Sertoli and theca cells differentiate adjacent to the testis cords and ovarian follicles, respectively, and it is thought that these structures secrete factors that influence the recruitment and control of the steroidogenic cells. Sertoli cells in the testis cords are strongly implicated in the control of Leydig cells in this manner, as Sertoli cells express the male sex-determining gene (Sry) and are able to recruit all other gonadal cells to the male fate during sex determination (Brennan and Capel 2004). Sertoli cells are also known to mediate the effects of 
Follicle Stimulating Hormone (FSH) on steroidogenesis and increase proliferation and survival of both embryonic and adult Leydig cells in culture (Saez 1994). In the ovary, granulosa cells from the follicles have been shown to induce proliferation and steroidogenesis in theca precursors in culture (Kotsuji and Tominaga 1994; Gelety and Magoffin 1997). A number of factors involved in Sertoli/Leydig cell or granulosa/theca cell communication have been identified (Gnessi et al. 1997; Knight and Glister 2006); however the processes underlying the local control of the recruitment and development of steroidogenic cells in the gonads are still unknown.

Both the testis and ovary derive from the same embryonic primordium, the bipotential gonad (Brennan and Capel 2004). As Leydig and theca cells have similar functions, it has been proposed that these endocrine cells share a common progenitor population and have similarities in their developmental pathways. However, many of the factors known to control the development of these cells do not appear to be conserved between the two populations. For example, while Desert hedgehog $(D h h)$ is required for normal Leydig cell development in the testis, $D h^{-/-}$ovaries are fertile and have normal theca cells (Clark et al. 2000). Reciprocally, Growth differentiation factor $9(G d f 9)$ is essential for theca cell development in the ovary yet not required for Leydig cells and fertility in the testis (Dong et al. 1996).

Platelet-derived growth factor receptor $\alpha$ (Pdgfr $\alpha)$ and its ligand $P d g f a$ are known to be required for Leydig cell development. Pdgfr $\alpha^{-/-}$males have reduced or absent fetal Leydig cells (Brennan et al. 2003). The global knockout of this receptor is lethal at early embryonic stages, making further assessment of the requirements of this pathway in Leydig cell difficult; yet some $P d g f a^{-/-}$males live to early adulthood and are observed to have fetal Leydig cells but fail to recruit adult Leydig cells at adolescence (Gnessi et al. 2000), indicating that the PDGF pathway acts in both the fetal and adult population. Interestingly, the PDGF receptors (Pdgfr $\alpha$ and $P d g f r \beta)$ are expressed in both Leydig and theca cells in many species, while PDGF ligands (Pdgfa, $P d g f b$, and $P d g f c$ ) are expressed in both testis cords and follicles (Gnessi et al. 1995; Loveland et al. 1995; Taylor 2000; Basciani et al. 2002; Yoon et al. 2006; Sleer and Taylor 2007). In culture, PDGF ligands induce proliferation and affect steroidogenesis in both Leydig and theca cells (Gnessi et al. 1997; Taylor 2000). Thus, the PDGF pathway could have a common role in the development of steroidogenic cells in both sexes; however mutations of the PDGF receptors $P d g f r \alpha^{-/-}$and Pdgfr $\beta^{-/-}$mice are lethal before follicle development in the ovary (Soriano 1994, 1997), and the requirements of this pathway in the ovary have yet to be determined.

To investigate mechanisms downstream from the PDGF pathway, transcriptional targets of PDGF have been identified and mutated in mice using gene trapcoupled microarray analysis (Chen et al. 2004). Interestingly, despite a wide range of predicted cellular functions, mutations in many of these PDGF target genes lead to phenotypes consistent with the known functions of the PDGF pathway, including the establishment of vascular integrity, skeletal patterning, and glomeruli development in the kidney (Schmahl et al. 2007). When we examined fertility in mice carrying mutations in 11 different PDGF target genes, mutations in two genes led to defects in male fertility, as might be expected from the known requirement for PDGF in Leydig cells. Unexpectedly, two mutations also led to defects in female fertility and three additional mutations lost female fertility when bred onto a $P d g f \mathrm{r}^{+/-}$background. All infertile mutations of PDGF targets exhibited reduction of hormone production from the gonads and defects in Leydig and/or theca cells. Thus we identified five new genes involved in the control of these steroidogenic cells. Furthermore, the requirement of multiple PDGF targets in both Leydig and theca cells and the effect of the Pdgfr ${ }^{+/-}$background on female fertility strongly suggested that the PDGF pathway has a conserved function in both Leydig and theca cells. To verify this, both PDGF receptors, Pdgfr $\alpha$ and $P d g f r \beta$, were conditionally deleted from the steroidogenic lineages. Pdgfr $\alpha$ was determined to be important in the development of both Leydig and theca cells. Interestingly, deletion of both Pdgfr $\alpha$ and Pdgfr $\beta$ from the steroidogenic lineages led to additional defects in the adrenal cortex. Thus, PDGF signaling is required for the development of steroidogenic cells in several different organs in the body and may represent a common mechanism in the control of multiple steroidogenic lineages.

\section{Results}

Mice carrying viable mutations in 11 PDGF target genes (listed in Table 1) were tested for fertility and reproductive phenotypes by housing mutant mice of either sex with wild-type mice of the opposite sex and monitoring females for vaginal plugs and pregnancy. Out of the 11 mutations tested, three were observed to lead to sterility. Plekha1 ${ }^{-/-}$mice were male sterile, Tiparp ${ }^{-/-}$mice were female sterile, and Sgpl1-/- mice were both male and female sterile (Table 1). To test for genetic interactions with the PDGF receptors, mice with homozygous mutations in PDGF target genes were crossed onto Pdgfra ${ }^{+/-}$ and/or $P d g f r \beta^{+/-}$backgrounds. Fertility was not affected by the loss of one copy of $P d g f r \beta$. However, three additional lines (Plekha1, Schip1, and BC058969) lost female fertility when crossed onto a $P d g f \mathrm{r \alpha}^{+/-}$background, indicating that $P d g f r \alpha$ and five different PDGF targets may also be involved in processes necessary for female fertility.

These five PDGF target genes have a wide range of predicted functions in the cell. Sgpl1 encodes an enzyme that irreversibly cleaves sphingosine-1-phosphate (Van Veldhoven 2000). Plekha1 has no known function, but has a pleckstrin homology $(\mathrm{PH})$ domain that may bind phosphoinositides (DiNitto and Lambright 2006). Tiparp contains a parp domain and may ADP-ribosylate protein targets (Ma et al. 2001). BC058969 contains cadherin domains and may function in cellular adhesion. Schip1 is known to bind neurofibromatosis type 2 (NF2) in Schwann cells and may link membrane proteins to the 
Table 1. Fertility in mice with mutations in PDGF targets

\begin{tabular}{|c|c|c|c|c|}
\hline Name & Symbol & $-1-$ & $-/-\beta \mathrm{R}^{+-}$ & $-/-\alpha \mathrm{R}^{+-}$ \\
\hline Sphingosine phosphate lyase 1 & Sgpl1 & $\begin{array}{l}\text { Male sterile } \\
\text { Female sterile }\end{array}$ & $\begin{array}{l}\text { Male sterile } \\
\text { Female sterile }\end{array}$ & $\begin{array}{l}\text { Male sterile } \\
\text { Female sterile }\end{array}$ \\
\hline Pleckstrin homology domain family A1 & Plekha1 & Male sterile & Male sterile & $\begin{array}{l}\text { Male sterile } \\
\text { Female sterile }(71 \% ; n=7)\end{array}$ \\
\hline TCDD-inducible poly (ADP-ribose) polymerase & Tiparp & Female sterile & Female sterile & Female sterile \\
\hline Schwannomin-interacting protein 1 & Schip1 & Fertile & Fertile & Female sterile $(45 \% ; n=11)$ \\
\hline cDNA sequence BC058969 & BC058969 & Fertile & Fertile & Female sterile $(35 \% ; n=17)$ \\
\hline Myosin IE & MyoIe & Fertile & Fertile & Fertile \\
\hline cDNA sequence BC055757 & BC055757 & Fertile & Fertile & Fertile \\
\hline AT-rich interactive domain $5 \mathrm{~B}$ & Arid5b & Fertile & ND & Fertile \\
\hline KRAB zinc finger protein $6 \mathrm{D}$ & Mzf6d & Fertile & ND & Fertile \\
\hline AXIN1 up-regulated 1 & Axud1 & Fertile & Fertile & ND \\
\hline Thioredoxin-interacting protein & Txnip & Fertile & ND & ND \\
\hline
\end{tabular}

(ND) Not determined.

cytoskeleton (Goutebroze et al. 2000). Despite their diverse cellular functions, all five genes affected similar reproductive processes.

PDGF targets are required for Leydig cell development and steroid production in the testis

We identified two genes with an effect on male fertility (Sgpl1 ${ }^{-/-}$and Plekha1 $\left.{ }^{-1-}\right)$. Both of these genes were expressed in the testis, both in testis cords and interstitial populations (Fig. 1). Testis morphology appeared normal at postnatal day 7 (P7) in both Sgpl1 ${ }^{-/-}$and Plekha1 ${ }^{-/-}$ mice (data not shown). However, by P20, a stage at which adult Leydig cells would normally be replacing the fetal population, irregularities were seen in the mutant testes, including reductions in the testis intersti- tium and gaps in the spermatocyte layers of the testis cords (Fig. 2A). By early adulthood (P42), gross changes in testis morphology were visible in both mutants, including a dramatic reduction in testis size, loss of spermatocytes from the testis cords, and loss of spermatogenesis (Fig. 2B,E). While Sgpl1 ${ }^{-/-}$and Plekha1 ${ }^{-/-}$testes had defects in the same structures and cell types, $S g p 11^{-/-}$exhibited a more severe phenotype. In Sgpl1 ${ }^{-/-}$testes at P42, multinucleated giant cells were observed throughout testis cords, and spermatogenesis and formation of spermatids appeared completely absent, while Plekha1 ${ }^{-/-}$testes had some areas of spermatid formation at this stage. However, Plekha1 ${ }^{-/-}$males were never fertile and presented a complete loss of spermatogenesis by $10 \mathrm{wk}$ of age (data not shown).

The reduction of the testis interstitium and loss of

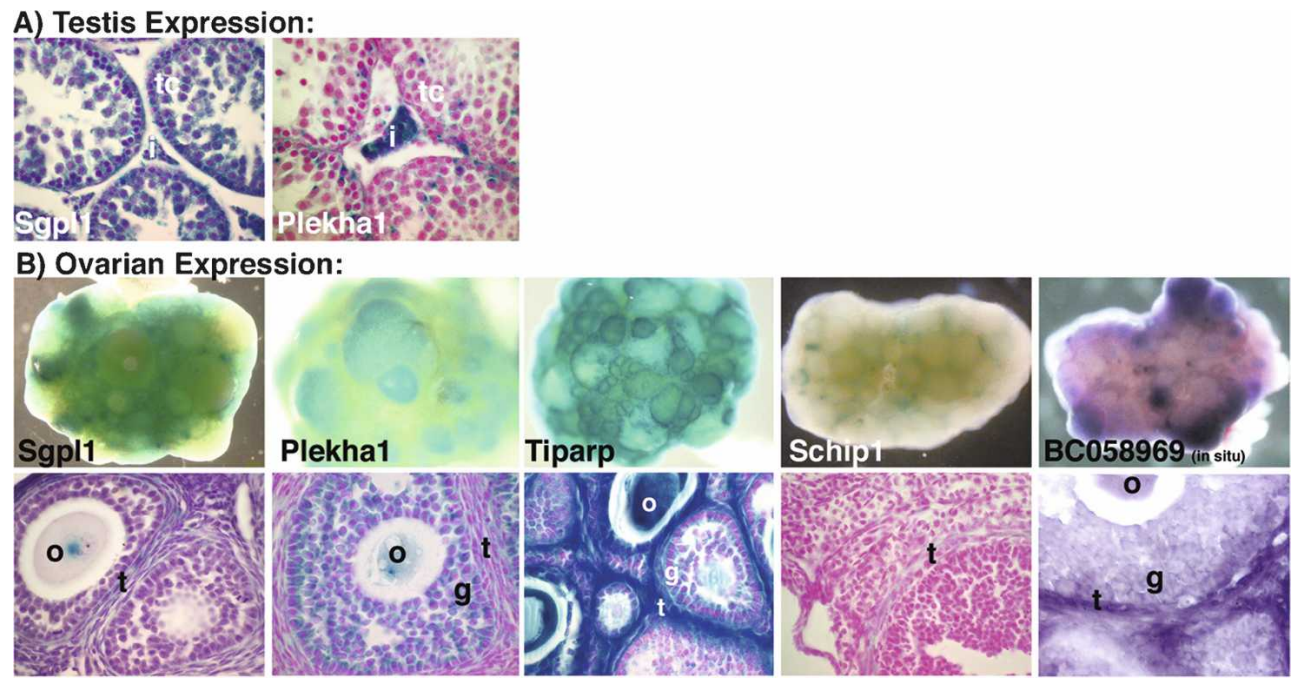

Figure 1. (A) Genes with male sterile phenotypes (Sgpl1 and Plekha1) are expressed in the testis, both within testis cords (tc) and interstitial cells (i). (B) Genes with effects on female fertility (Sgp11, Plekha1, Tiparp, Schip1, and BC058969) are expressed in the ovary, as seen in whole mounts (top row) or sections (bottom row). Many of these genes are expressed within the oocyte (o) and granulosa $(\mathrm{g})$ cells, and all are expressed within theca $(\mathrm{t})$ cells. Expression patterns were determined by X-gal staining (blue), which detects expression of the $\beta$-geo reporter from the gene trap vector, shown in heterozygous mice. Expression of $B C 058969$ was detected using in situ hybridization; sample is from wild-type mouse. X-gal stained sections were counterstained with nuclear fast red for contrast. 
Schmahl et al.
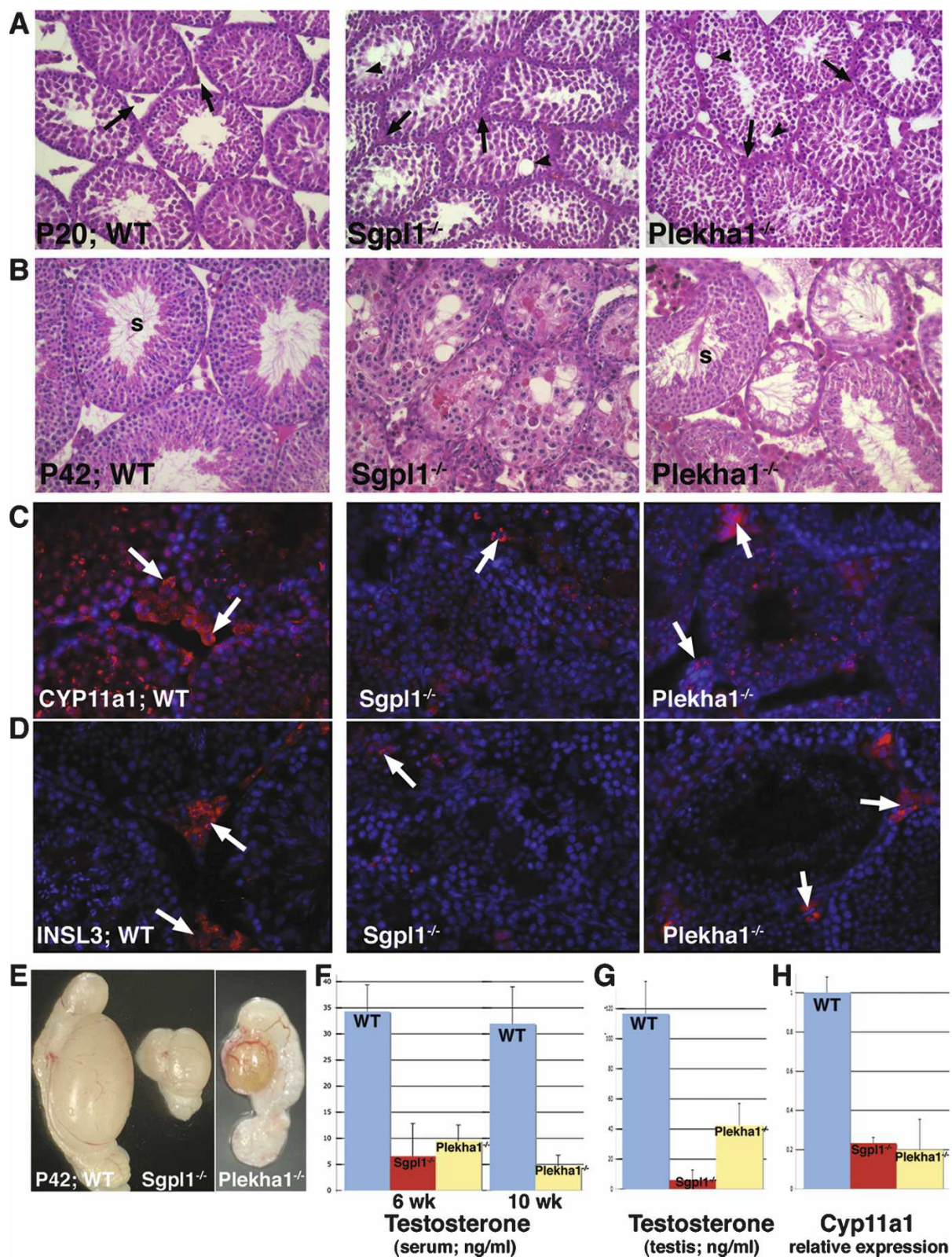

G

H

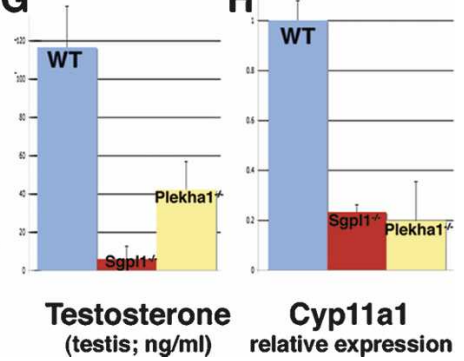

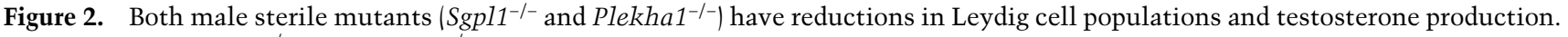
(A) At P20, both Sgpl1 $1^{-/-}$and Plekha1 $1^{-/-}$show reduction of the testis interstitium (arrows) and gaps in the spermatocyte layers of the testis cords (arrowheads). (B) By adulthood (P42), the loss of spermatogenesis is visible in the testis cords in both mutants. However, Plekha1 $1^{-/-}$testes have some areas of spermatid (s) formation. Antibodies against CYP11a1 (C; red) and INSL3 (D; red) label Leydig cells in the adult testis interstitium (arrows) and indicate a reduction in the numbers of Leydig cells in Sgpl1 ${ }^{-/-}$and Plekha1 ${ }^{-/-}$testes. CYP11a1 is also detected in some spermatocytes within the testis cords. Immunofluorescent sections are counterstained with DAPI

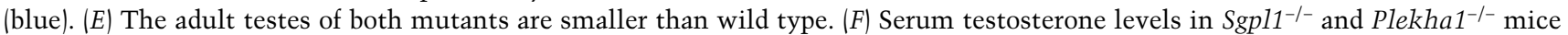
are lower than wild type at 6 and $10 \mathrm{wk}$ of age. $(G)$ As testosterone can also be produced from other areas of the body, testosterone was also measured in extractions from the testes of these mutants and was lower than wild type. (H) Using real-time PCR, Cyp11a1

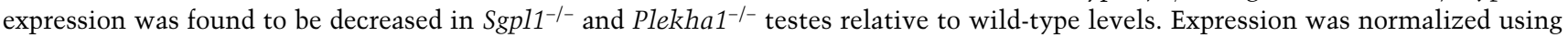
$U b c$ expression in each sample.

spermatogenesis observed in both $S g p 11^{-/-}$and Plekha1 ${ }^{-1-}$ testes was consistent with defects in Leydig cells and the loss of testosterone production. Therefore, Leydig cells were examined using two Leydig cell markers, Cytochrome P450, family 11, subfamily a, polypeptide 1 (CYP11a1) and Insulin-like 3 (INSL3). CYP11a1 is a steroidogenic enzyme that catalyzes an early step in the biosynthesis of steroid hormones and is expressed in steroidogenic cell types, including both fetal and adult Leydig cells. INSL3 (also known as Relaxin-like factor) is necessary for testicular descent and is secreted specifically by mature fetal and adult Leydig cells (Balvers et al. 
1998). Using these markers, Leydig cells were found to be reduced in the adult testes of both $S g p 11^{-1-}$ and Plekha1 ${ }^{-/-}$mice (Fig. 2C,D). A reduction in Cyp11a1 expression was also observed using real-time PCR. Consistent with the reduction in Leydig cells, testosterone lev-

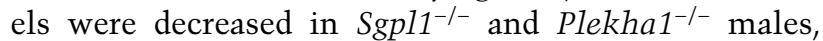
both in serum and in extractions from testes (Fig. 2F,G).

In both Sgpl1-/- and Plekha1-/- mice, testis morphology and male development appeared normal before P20, indicating that fetal Leydig cells were present. However, examination of Leydig cell markers CYP1la1 (Supplemental Fig. 1) and INSL3 (data not shown) at earlier stages indicated that Leydig cell numbers are reduced before adulthood. This reduction was visible as early as P7, before the appearance of the adult Leydig cell population, and continued through stages when adult cells would normally be replacing the fetal population (P14 and P21). Thus, Sgpl1 and Plekha1 function in both fetal and adult Leydig cell populations.

\section{PDGF targets are required for theca cell development and steroid production in the ovary}

Although members of the PDGF pathway are known to be involved in testis development, this pathway was not known to be required in the ovary. Thus it was somewhat surprising that mutations in two PDGF target genes lead to female sterility (Sgpl1 and Tiparp) and that an additional three mutations lost female fertility to a varying degree when bred onto a $P d g f \mathrm{ra}^{+/-}$background (Plekha1, Schip1, and BC058969) (Table 1). Despite their divergent cellular functions, four of the female sterile

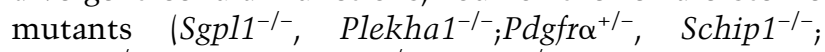
Pdgfra ${ }^{+/-}$, and $\left.B C 058969^{-/-} ; P d g f \mathrm{ra}^{+/-}\right)$had very similar ovarian phenotypes (Fig. 3) and each was consistent with loss of estrogen production. The ovaries of these mutant mice were unusually small, and later stage antral follicles were decreased in numbers. No corpora lutea were present in $\mathrm{Sgpl1}^{-/-}$and Plekha1 ${ }^{-/-}{ }_{;} P d g f \mathrm{r \alpha}^{+/-}$ovaries, indicating that ovulation did not occur. In the mutants with only a partial loss in fertility (Schip $1^{-/-} ; P d g f r \alpha^{+/-}$ and $\mathrm{BCO58969}^{-/-}{ }$Pdgfr $\mathrm{\alpha}^{+/-}$) (see Table 1), a few corpora lutea were occasionally observed, but the number and incidence of these structures was strikingly reduced. In ovaries from mice older than $8 \mathrm{wk}$, the stroma appeared hyperplasic, containing multiple atretic follicles. The uteri of these four female sterile lines were hypoplasic, and sections indicated that the major uterine layers were present, but underdeveloped (Supplemental Fig. 2).

One female sterile mutant $\left(\right.$ Tiparp $\left.^{-/}\right)$exhibited very different ovarian morphology from the others (Fig. 3). Instead of small ovaries, Tiparp ${ }^{-1-}$ ovaries appeared enlarged, often exhibited an abnormally large number of late stage antral follicles and corpora lutea, and occasionally developed hemorrhagic cysts. In Tiparp ${ }^{-/-}$females, the length of the estrus cycle was greatly protracted, lasting up to $4 \mathrm{~d}$ instead of the normal $13 \mathrm{~h}$ length. Among 16 Tiparp $^{-/-}$females set up with males during a 3-mo period, six pregnancies were observed. These occasional pregnancies lasted between 21 and $23 \mathrm{~d}$ instead of $19 \mathrm{~d}$, at which point the pups were either born dead and often partially reabsorbed or the mother was sacrificed due to declining health. The sizes of these litters were also unusually small $\left(2.8 \pm 0.5\right.$ from Tiparp $^{-/-}$females vs. $9.3 \pm 0.7$ from wild type).

Both the anovular phenotype seen in $S g p 11^{-/}$, Plekha1 ${ }^{-/} ;$Pdgfr $^{+/-}, \quad$ Schip1 ${ }^{-/-}$;Pdgfr ${ }^{+/-}$, and $B C 058969^{-/-}{ }_{i} P d g f \alpha^{+/-}$ovaries and the polyfollicular phenotype seen in Tiparp ${ }^{-/-}$ovaries are consistent with altered hormone levels. The anovular phenotypes are similar to those seen in mice with decreases in estrogen levels (Fisher et al. 1998; Hasegawa et al. 2000; Toda et al. 2001), while the enlargement of the ovary, increased follicle development, the formation of cysts, and persistent estrus in Tiparp ${ }^{-/-}$ovaries is consistent with increases in hormone levels, particularly androgens. Using $\beta$ gal staining or in situ hybridization, all of these genes were expressed in the steroidogenic theca cell layers (Fig. 1). Therefore theca cells and hormone levels were examined in the female sterile mutants.

Using antibodies against CYP11al and chondroitin sulfate proteoglycan 4 (CSPG4), theca cells were observed to be reduced in the female sterile lines with little

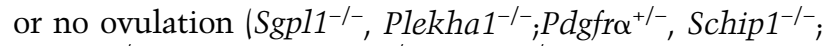
Pdgfra ${ }^{+/-}$, and $\mathrm{BCO58969-/-} \mathrm{Pdgfr \alpha}^{+/-}$) (Fig. 3C; Supplemental Fig. 3). Tiparp ${ }^{-/}$ovaries did not appear to have altered theca cell numbers using either marker. Estradiol levels were reduced in all female sterile lines (Fig. 3D). In mutants that were only partially infertile (Schip1 $1^{-/-}$; Pdgfra ${ }^{+-}$and $B C 058969^{-/-} ; P d g f \mathrm{ra}^{+/-}{ }^{-}$, estradiol levels varied substantially more than in the more fully penetrant lines.

\section{PDGF target genes may regulate differentiation and the control of steroidogenesis}

Despite reductions in the markers of steroid production and theca differentiation, the distinctive theca layers were still observed surrounding follicles in the ovaries of all female sterile mutants (data not shown), indicating that theca cells were still recruited to the follicles in the absence of these genes. Furthermore, patterns of proliferation and cell death did not appear to be altered in the gonads of male or female sterile mutants when examined at several different stages (data not shown), except at late stages in male mutants, where elevated levels of cell death in the testis cords reflect the loss of spermatocytes and are secondary to the lack of testosterone /Gnessi et al. 2000). Instead, the problem may lie in differentiation or acquisition of the capacity to produce steroid hormones.

Steroidogenic cell differentiation and hormone production by the testis and ovary can be affected by the circulating levels of luteinizing hormone (LH) and FSH, two gonadotropins secreted by the pituitary gland. However, the levels of LH and FSH in male and female sterile mutants was not lower than wild type (Supplemental Fig. 4; data not shown); thus the decrease in steroid production in the gonads is not likely to be due to secondary phenotypes in other organs of the endocrine system. 


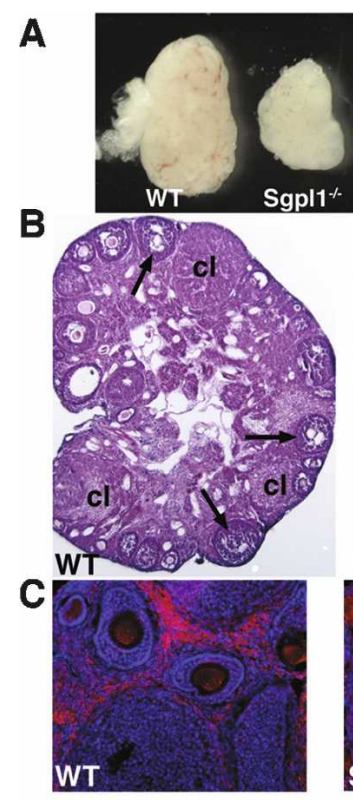

D
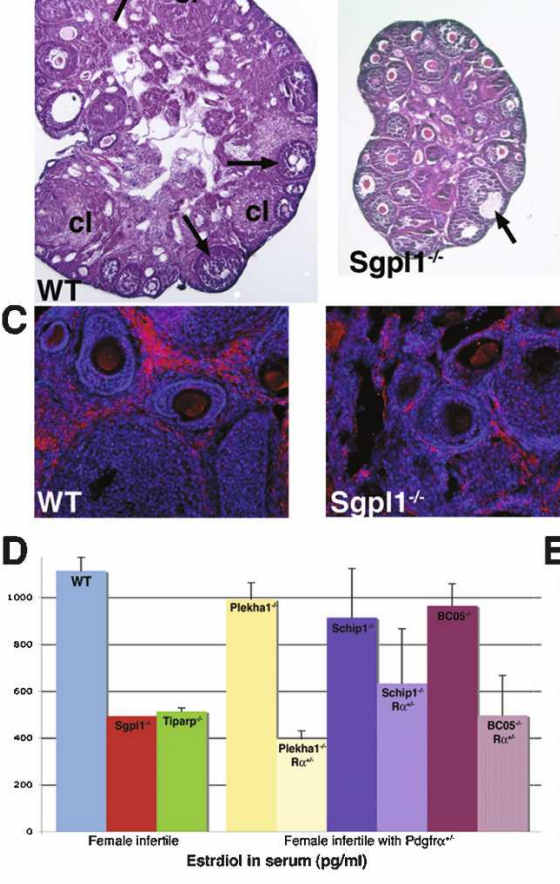
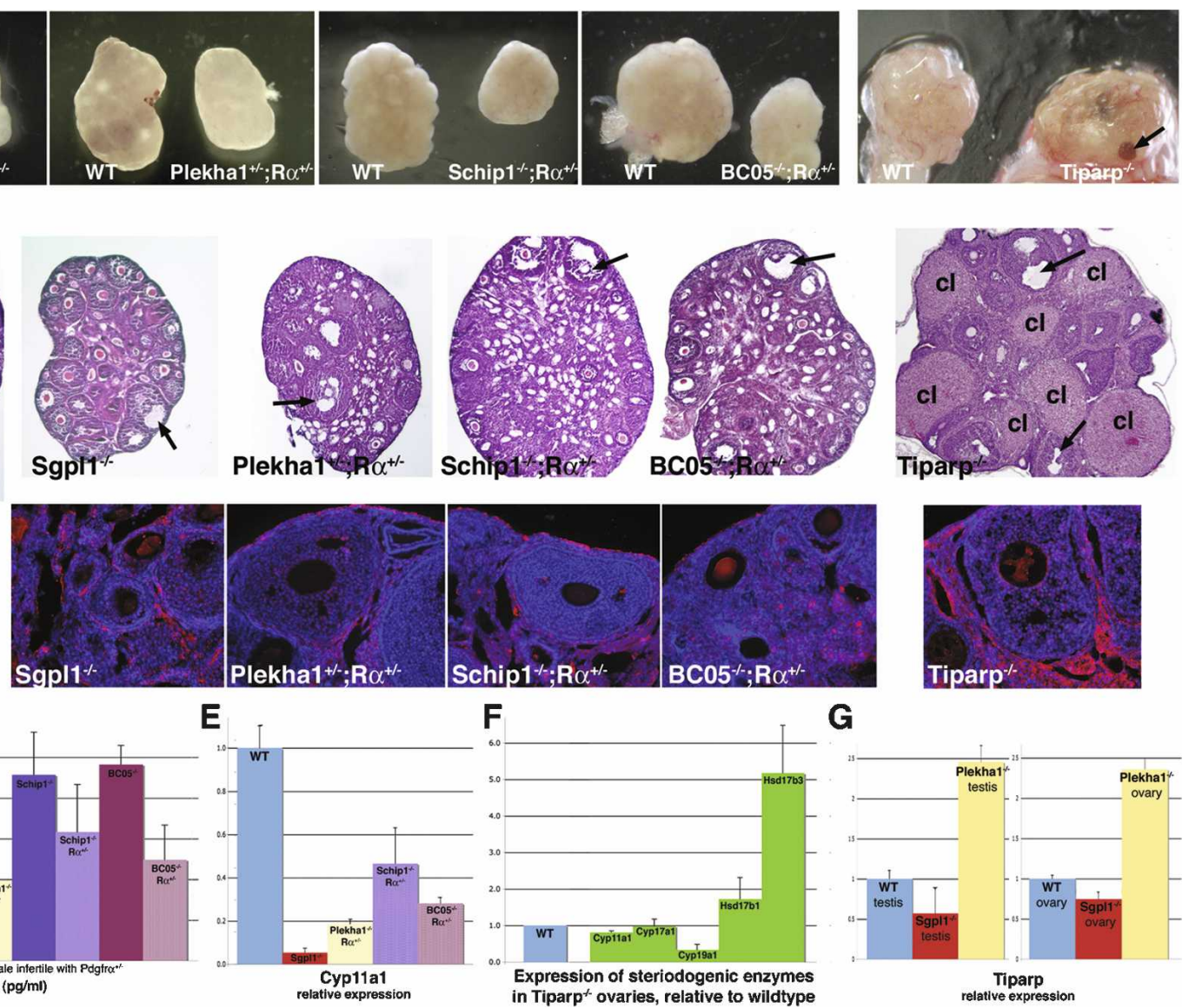

G

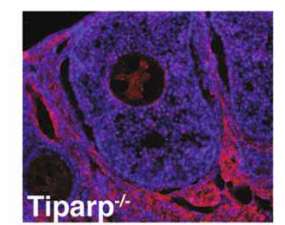

Tiparp

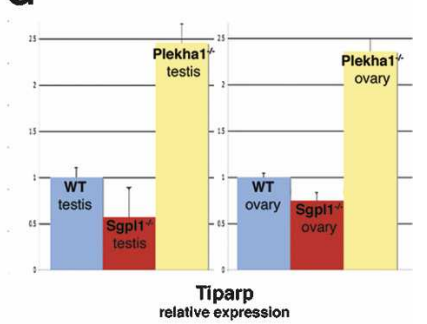

Figure 3. Female sterile mutants exhibit defects in ovarian size, follicle development, ovulation, theca cells, and estrogen production. (A) Whole-mount ovaries from female sterile mutants are shown with a wild-type ovary of equivalent age. Most female sterile mutant ovaries are smaller than wild type, with the exception of Tiparp ${ }^{-1-}$ ovaries, which are larger and occasionally exhibit hemorrhagic cysts (arrow). (B) Ovarian sections indicate that follicle development still occurs in the mutants, but fewer antral follicles (examples indicated by arrows) and corpora lutea $(\mathrm{cl})$ are observed in most female sterile mutants. However, Tiparp ${ }^{-/-}$ovaries show increased follicle development, with numerous antral follicles and corpora lutea. (C) Using an antibody against CYP11a1 (red), reduced theca cell numbers were observed in the ovaries of most female sterile mutants, with the exception of Tiparp ${ }^{-/-}$ovaries. Immunofluorescent sections are counterstained with DAPI (blue). (D) Serum estradiol levels were decreased in all female sterile mutants. As would be expected, the mutations that only lost fertility when crossed onto a $P d g f r \alpha^{+/-}$background had roughly normal estradiol levels as single mutants and lowered estradiol levels when crossed onto a Pdgfr ${ }^{+/-}$background. (E) Using real-time PCR, Cyp11a1 expression was found to be decreased in some female sterile mutant ovaries. (F) In Tiparp ${ }^{-/}$ovaries, the expression levels of steroidogenic enzymes varied. The expression of both Cyp11a1 and Cyp17a1 were close to wild-type levels, Cyp19a1 was lower than wild type, and both $H s d 17 b 1$ and $H s d 17 b 3$ were increased. The expression of each enzyme is shown relative to wild-type levels (set at 1.0 and represented by the blue bar). $(G)$ Tiparp expression is increased in both Plekha1 $1^{-/-}$testes and ovaries relative to wild type. All samples shown were taken from mice between 6 and $12 \mathrm{wk}$ of age, with the exception of $S g p l 1^{-/-}$. Due to the early mortality of $\operatorname{Sgp} 11^{-/-}$mice, these samples were taken between 5 and $6 \mathrm{wk}$.

In the testis, adult Leydig cells are thought to differentiate from a vascular smooth muscle cell (VSMC) population (Davidoff et al. 2004). Interestingly, PDGF signaling is known to control the development of VSMCs in many organs, suggesting that this signaling pathway could control the early differentiation of steroidogenic cells from a VSMC precursor population. To determine if the selected PDGF targets affect VSMC development in the gonads, these cells were examined in both male and female sterile mutants using two different markers; $\alpha$ smooth muscle actin (ASMA) and Desmin. In the testes of Plekha1 ${ }^{-/-}$mice (Supplemental Fig. 5) and ovaries of Sgpl1 ${ }^{-1-}$, Plekha1 ${ }^{-1-} ;$ Pdgfra ${ }^{+-}$, Schip1 ${ }^{-1-}$;
Pdgfra ${ }^{+/-}$, and $\mathrm{BCO58969-/-}^{-} \mathrm{Pdgfr \alpha ^{+/- }}$ mice (Supplemental Fig. 3), reduced labeling of VSMCs was seen around vasculature. These cells did not appear to be reduced in the ovaries of Tiparp $^{-1-}$ mice. Thus mutations in PDGF targets that reduce the numbers of steroidogenic cells also reduce the number of VSMC in the gonads, suggesting that the development of these two cell types is jointly controlled through this signaling pathway.

To determine the relative levels of steroidogenic enzymes, real-time PCR was used on RNA collected from ovaries from female sterile mice. As expected from the decrease in CYP11a1 antibody labeling, Cyp11a1 expression in mutants with little or no ovulation was lower 
than wild type, with mutants with more fully penetrant phenotypes (Sgpl1 ${ }^{-/-}$and Plekha1 $\left.{ }^{-/} ;{ }^{-} P d g f r \alpha^{+/-}\right)$having lower expression than those with less penetrant pheno-

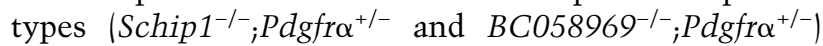
(Fig. 3E). However, Tiparp ${ }^{-/-}$ovaries had close to normal levels of enzymes that function early in the steroid biosynthetic pathway (Cyp11a1 and Cyp17a1) (Fig. 3F). Instead, other enzymes were affected in this mutant. The levels of CYP19a1, which converts androgens to esterone (a precursor to estradiol), was roughly two-thirds lower than wild type, which may explain the decrease in estradiol levels. Interestingly, levels of the $17 \beta-H y d r o x y s t e r-$ oid dehydrogenases Hsd17b1 and Hsd17b3 were increased. $H s d 17 b 3$ is considered an androgenic enzyme and is normally expressed in the testis, where it is responsible for reducing androgens to testosterone. The repression of this enzyme in the ovary is critical for the sexually dimorphic production of estrogen and testosterone, as mutants that express $H s d 17 b 3$ in the ovary undergo a transformation of theca cells to Leydig-like cells, secrete androgens, and have enlarged polycystic ovaries (Couse et al. 2006), similar to the phenotype seen in Tiparp $^{-/-}$ovaries.

The up-regulation of Hsd17b3 in Tiparp ${ }^{-/-}$ovaries suggests that Tiparp may be involved in the repression of this androgenic enzyme in the ovary. Interestingly, although mutation of Tiparp does not affect male fertility or testosterone production in the male (data not shown), the loss of one copy of Tiparp rescues male fertility in Plekha1 ${ }^{-1-}$; Tiparp $^{+/-}$mice, indicating that a key function of Plekha1 in the testis may be to suppress Tiparp. Supporting this hypothesis, Plekha1 ${ }^{-/}$testes and ovaries were found to have Tiparp expression levels at two to three times wild type (Fig. 3G). This increase in Tiparp expression was not due to changes in cellular composition of the gonads (i.e., the loss of sperm in the male or corpora lutea in the female) as Sgp11 ${ }^{-/-}$testes and ovaries had Tiparp expression levels not significantly different or somewhat lower than wild type. Thus Plekha1 and Tiparp may operate in the same pathway in the control of the male steroidogenic pathway (Supplemental Fig. 6).

\section{Pdgfro is required in both Leydig and theca cells}

In the ovary, two PDGF target genes are required for normal theca cell development and hormone production, and the loss of one copy of Pdgfr $\alpha$ decreases hormone levels in mice with mutations in three other PDGF target genes. As both PDGF receptors are expressed in theca cells (Supplemental Fig. 7), these results suggest that PDGFR $\alpha$ has a function in theca cells in the ovary. To investigate this possibility, conditional alleles of Pdgfr $\alpha$ $\left(P d g f r \alpha^{f l}\right)$ (Tallquist and Soriano 2003) were crossed with mice expressing Cre from the Steroidogenic factor-1 promoter (Sf1, officially designated Nr5a1) (Bingham et al. 2006). To verify the specificity of its expression and function in the gonads, Sf1-Cre mice were crossed to the ROSA26R Cre reporter line. Using X-gal staining, Cre activity was detected in both Leydig and theca cells, with mosaic expression in Sertoli cells and granulosa cells of late stage follicles (Fig. 4A,I).

Sf1-Cre;Pdgfr ${ }^{f l-/-}$ mice were found to have defects in the normal development of steroidogenic cells in both the testis and ovary. In Sf1-Cre;Pdgfro ${ }^{f l-/}$ testes, histological and cellular defects were visible by early adulthood (P42). At this stage, Sf1-Cre;Pdgfra ${ }^{f l-/-}$ testes were abnormally small, and areas of spermatocyte loss from the testis cords were evident (Fig. 4). Small numbers of mature sperm were observed within some testis cords; however, few sperm were found within the epididymis. A reduced number of adult Leydig cells were detected in Sf1-Cre;Pdgfro ${ }^{f l-/}$ testes, and Cyp11a1 expression was lower than in wild type, indicating that Pdgfro is indeed necessary for the normal development of the adult Leydig cell population.

At embryonic stages (E12.5-E14.5), testis cord formation was delayed in Sf1-Cre; $P d g f r \alpha^{f l-/-}$ testes and fewer steroid-producing cells were observed (Supplemental Fig. 8). These phenotypes are similar to the defects observed in Pdgfra ${ }^{-/-}$testes at these stages (Brennan et al. 2003), indicating that many of the effects of $P d g f r \alpha$ in the testis are cell-autonomous to steroid-producing cells. However, the defects in Sf1-Cre;Pdgfra ${ }^{f l-l-}$ testes appear to be somewhat less severe than in $P d g f r \alpha^{-/-}$testes at these stages, suggesting that other cell types may be involved. Alternatively, the testis phenotypes in $P d g f \mathrm{r \alpha}^{-/-}$mice may simply be amplified by the other acute phenotypes apparent in Pdgfro $\alpha^{-/-}$embryos, which usually die around this stage (Soriano 1997).

Sf1-Cre;Pdgfro ${ }^{f l-/-}$ ovaries at 6-8 wk displayed phenotypes consistent with theca cell defects and similar to those seen in mice with mutations in PDGF targets, including small ovaries, underdeveloped uteri, decreased follicle development, and no evidence of ovulation (Fig. 4J-L; data not shown). The theca cells were reduced in the maturing follicles of these ovaries, and both Cyplla1 expression and estradiol levels were lower than wild type (Fig. $4 \mathrm{M}-\mathrm{O}$ ). Therefore, as predicted by the female sterile phenotypes of some PDGF targets, Pdgfro also has a critical role in theca cells.

While the conditional deletion of Pdgfr $\alpha$ led to reductions in steroid-producing cells significant enough to affect fertility in both sexes, it did not lead to the total loss of these cells. Leydig cells and areas of spermatogenesis were still detectable in the testis, and a thin, broken theca interna was detectable in the ovary (Fig. 4). Additionally, the phenotypes seen in Sf1-Cre;Pdgfro ${ }^{f l-1-}$ testes and ovaries at early adulthood (6 wk) were recoverable, and most Sf1-Cre;Pdgfra ${ }^{f 1-/-}$ mice became fertile between 3 and 6 mo of age. At 6 wk Sf1-Cre;Pdgfro ${ }^{f l-/-}$ testes were smaller than wild type, yet by $10 \mathrm{wk}$ these testes appeared normal and had increased testosterone (Fig. 5). Thus, loss of Pdgfra results in a delay of fertility and hormone production.

We hypothesized that the recovery of fertility in Sf1Cre;Pdgfro ${ }^{f l-/-}$ mice might be due to recovery of Pdgfra expression, resulting from expansion of cells in which deletion had not occurred. Alternately, $P d g f r \beta$ may be able to compensate for the loss of $P d g f r \alpha$, as $P d g f r \beta$ has a 
Schmahl et al.
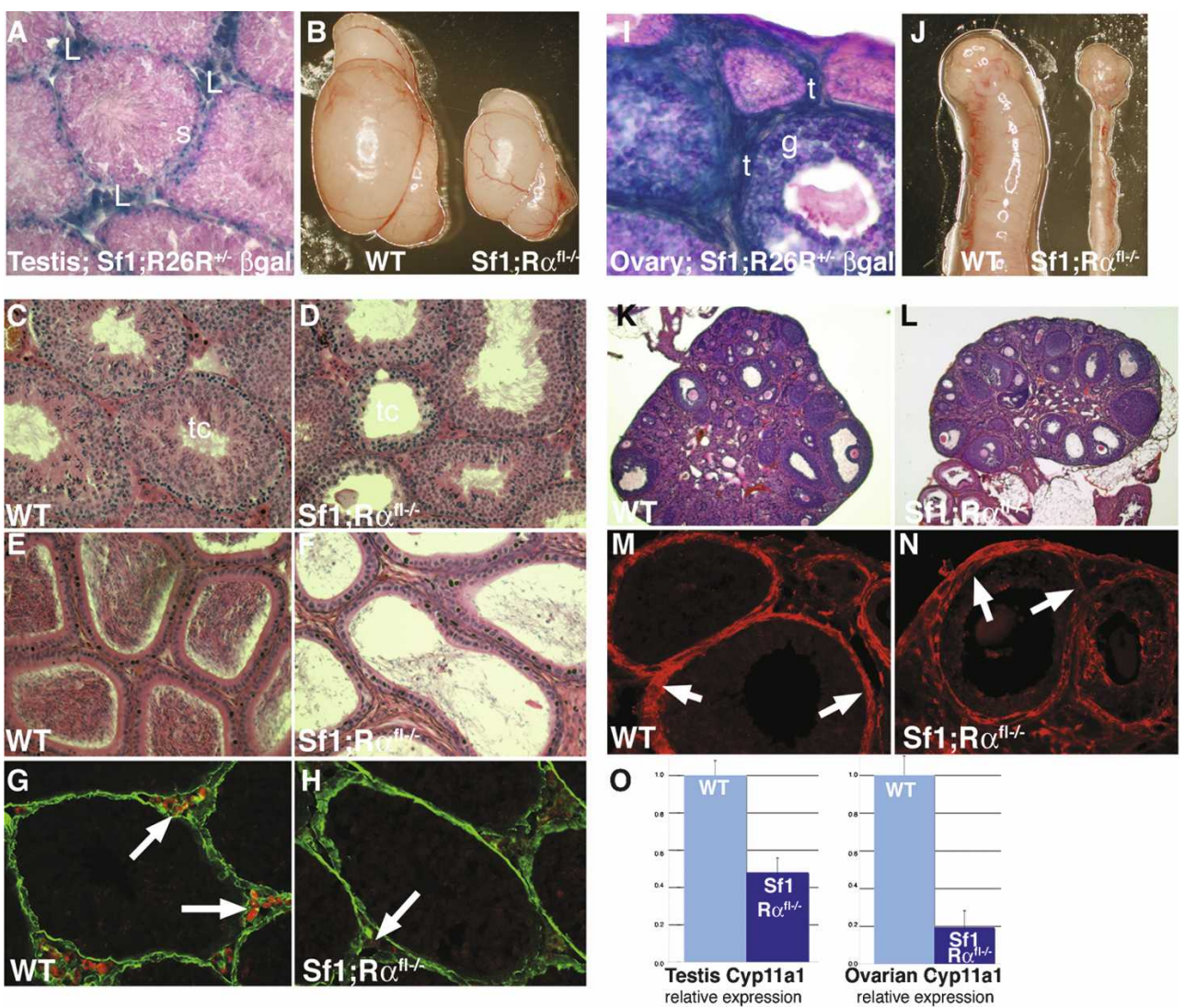

Figure 4. Conditional knockout of $P d g f r \alpha$ leads to defects in the testis and ovary. $(A, I)$ Using Xgal staining, Sf1-Cre (blue) is detected in Leydig (1) cells and theca ( $\mathrm{t}$ ) cells. Sertoli (s) and granulosa cells (g) have mosaic expression. (B-F) Testes of $S f 1-C r e ; P d g f r \alpha^{f l-/-}$ mice are smaller than wild type $(B)$, show signs of spermatocyte loss in the testis cords $(\mathrm{tc})(C, D)$, and have greatly reduced numbers of sperm stored in the epididymis $(E, F)$. $(G, H) S f 1$-Cre; $P d g f r \alpha^{\text {fl- }-1-}$ testes have reduced numbers of Leydig cells (red, arrows), detected with an antibody against INSL3. An antibody against Desmin (green) outlines the testis cords. (J) Sf1-Cre; Pdgfro ${ }^{\text {fl- } /-}$ ovaries are small and have hypoplasic uteri. $(K, L)$ Follicle development is observed, but no corpora lutea are present. $(M, N)$ Using an antibody against CSPG4 to label the theca interna, these cells are reduced in $S f 1-C r e ; P d g f r \alpha^{\mathrm{fl}-/-}$ ovaries. (O) Expression of the steroidogenic enzyme Cyp11a1 is reduced in Sf1-Cre; $P d g f r \alpha^{\mathrm{fl}-/-}$ testes and ovaries, relative to wild-type levels. Expression was normalized using $U b c$ expression.

similar gonadal expression pattern (Supplemental Fig. 7) and is known to activate similar pathways in the cell (Klinghoffer et al. 2001). To differentiate between these possibilities, we used real-time PCR and in situ hybridization to examine Pdgfr $\alpha$ and Pdgfr $\beta$ expression. We found that Pdgfra levels did not increase between 6 and 10 wk in Sf1-Cre;Pdgfro ${ }^{f l-/-}$ gonads (Fig. 5; data not shown). However, Pdgfr $\beta$ expression increased in $S f 1$ Cre; Pdgfr ${ }^{f l-l-}$ samples over this period. In the testes, increased $P d g f r \beta$ expression was found only in mice that also had increased testosterone, suggesting that an increase in $P d g f r \beta$ expression might compensate for the loss of $P d g f r \alpha$ in steroidogenic cells, and thus that $P d g f r \beta$ may have a function in these cells.

\section{Both Pdgfra and Pdgfr $\beta$ receptors are necessary for multiple steroidogenic populations}

To determine if $P \operatorname{dgfr} \beta$ has a role in steroidogenic cells, we generated a conditional allele of $P \operatorname{dgfr} \beta\left(P \operatorname{dgfr} \beta^{f l-l-}\right)$ (Supplemental Fig. 9) and crossed it to Sf1-Cre and
Pdgfra ${ }^{f l-l-}$ mice. Sf1-Cre; Pdgfr $\beta^{f l-/-}$ mice were both viable and fertile, indicating that removal of this receptor alone did not affect fertility. However, few Sf1-Cre; $P d g f r \alpha^{f l-I-} ; P d g f r \beta^{f l-/-}$ mice were recovered after birth (Supplemental Table 1). Sf1-Cre; Pdgfra ${ }^{f l-/-}$;Pdgfr $\beta^{f l-/-}$ mice were recovered before birth (at E18.5), indicating that these deletions can be perinatally lethal when combined. This lethality is unlikely to be due to a problem in gonad development, as the gonad is not necessary for viability; however, the Sf1-Cre line expresses Cre in other steroid-producing organs in the embryo, including the adrenal cortex (Bingham et al. 2006). This organ secretes hormones important in metabolism and nutrient absorption, such as corticosteroids and catecholamines, and is necessary for postnatal viability.

Using the ROSA26R Cre reporter line, Sf1-Cre activity was detected in the adrenal gland, both at embryonic and adult stages (Fig. 6A). Just before birth (E18.5) the adrenal glands of Sf1-Cre; Pdgfr ${ }^{f l-1-} ; P d g f r \beta^{f l-l-}$ mice appeared small, with a reduced adrenal cortex (Fig. 6B,C). Using CYP1la1 as a marker of steroidogenesis, reduced num- 

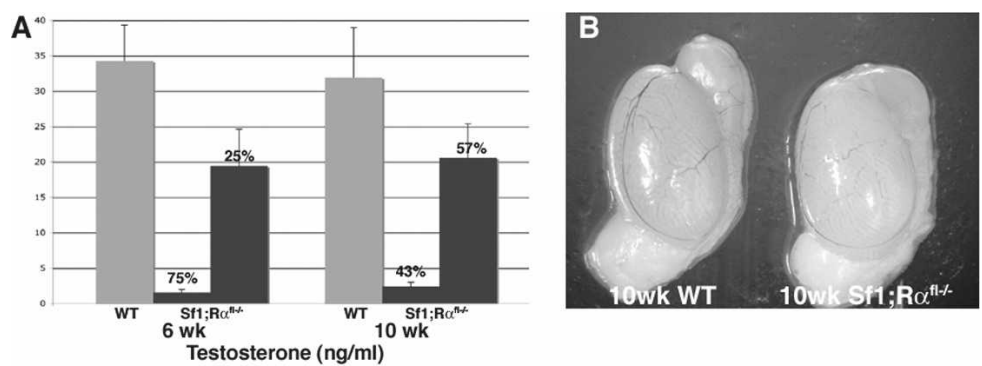

C
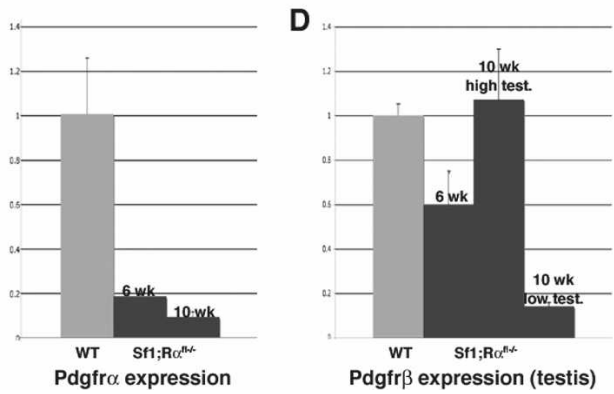

E

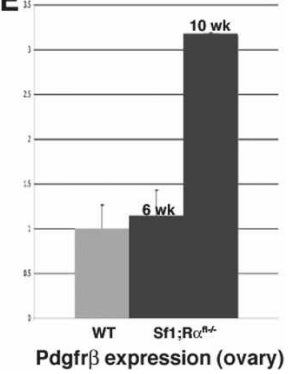

Figure 5. Sf1-Cre; $P d g f r \alpha^{\mathrm{fl}-/-}$ testes and ovaries recover fertility. (A) At 6 wk of age, testosterone was low in most Sf1-Cre; $P d g$ fra ${ }^{\text {fl- } /-}$ testes (12 out of 16 , or $75 \%$, using the mean at 6 wk as a cutoff). However by $10 \mathrm{wk}$, higher testosterone levels were detected in most Sf1-Cre; $P d g f r \alpha^{\mathrm{fl}-/-}$ testes (eight out of 14 , or $54 \%)$ (B) By $10 \mathrm{wk}, S f 1-C r e ; P d g f r \alpha^{\mathrm{fl}-/-}$ testes appeared normal. (C) Pdgfro expression did not increase in $S f 1$ Cre; $P d g f r \alpha^{\mathrm{fl}-/-}$ testes over this period. $(D) P d g f r \beta$ expression changed in Cre; $P d g f r \alpha^{\text {fl- } /-}$ testes over time and was observed to be higher in samples with high testosterone levels than in samples with low testosterone levels by 10 wk. $(E)$ In the ovary, $P d g f r \beta$ expression is close to wild type at $6 \mathrm{wk}$ of age and increases by $10 \mathrm{wk}$ of age. Wild-type samples are a pool of samples between 6 and $10 \mathrm{wk}$. Expression levels were normalized for each sample using $U b c$. bers of steroid-producing cells were observed in Sf1Cre;Pdgfro ${ }^{f l-l-} ; P d g f r \beta^{f l-l-}$ adrenal glands at this stage (Fig. 6D). Few steroid-producing cells were also detected in the testes at this time, and the testes themselves appeared small and frequently hemorrhagic. Therefore the joint actions of Pdgfr $\alpha$ and $P d g f r \beta$ are necessary for the development of steroidogenic cells in several steroid-producing organs in the body, including the ovary, testis, and adrenal gland, indicating that this pathway may be part of a common mechanism in the control of these different populations.

\section{Discussion}

PDGF receptors and their ligands are essential for the development and normal function of a wide variety of cell types and tissues, including VSMCs, neural crest cells, myelination of the central nervous system, and the proper patterning of the skeleton, lung, and kidney (Hoch and Soriano 2003; Andrae et al. 2008). The transcriptional targets of PDGF signaling, identified in fibroblasts, have been shown to control the same processes as the PDGF receptors in vivo (Schmahl et al. 2007). For example, when 12 different targets of PDGF signaling were mutated, four of these genes were shown to control migration of mesangial cells into glomerular capsules in the kidney, a process controlled by PDGFR $\beta$. In the craniofacial skeleton, mutation of seven different PDGF targets were shown to reduce the bones at the midline, structures that are known to be dependent on PDGFR $\alpha$. Although disruption of PDGF target genes affected the same processes as the PDGF receptors, most mutations in these target genes were less severe than mutation of the receptors and at least partially viable. Thus, examining the function of growth factor target genes has the potential to reveal later functions of the pathway.

In this study, we showed that five PDGF target genes are essential for the normal development of steroid-pro- ducing cells in the gonads. Two PDGF target genes (Sgpl1 and Plekha1) have a role in the steroid-producing cells of the testis, the Leydig cells. This is consistent with the known requirement of PDGF in this cell type. As would be expected from the phenotypes in other organs, the gonadal phenotypes observed in mice with mutations in PDGF target genes appear somewhat attenuated from the phenotypes in $P d g f r \alpha^{-/-}$gonads. Along this line, complete loss of Pdgfra results in the absence or dramatic reduction of fetal Leydig cells (Brennan et al. 2003), while the loss of the two PDGF target genes appear to have a reduced, but still functional, fetal Leydig cell population. Interestingly, the adult Leydig cell population appears to be more strongly affected. The requirement of Pdgfra in this adult population was less well known due to the embryonic lethality of $P d g f r \alpha^{-/-}$mice, but the phenotypes of mutations of these two PDGF target genes are similar to mice missing the PDGF ligand Pdgfa (Gnessi et al. 2000), and Sgpl1-/-, Plekha1 ${ }^{-/-}$, and $P d g f a^{-/-}$testes all exhibit loss of the adult Leydig cell population, reductions in testosterone production, and the subsequent loss of spermatogenesis and fertility by early adult stages. Thus we identified two targets of PDGF that are essential for the development of the steroidogenic cells of the testis and may act downstream from the PDGF pathway in the control of these cells.

In the ovary, mutation of five different PDGF target genes affected ovarian function, either alone (Sgpl1 and Tiparp) or on a Pdgfr $\alpha^{+/-}$background (Plekha1, Schip1, and BC058969). These genes were shown to affect a steroid-producing cell type in the ovary, the theca cell, and all female sterile mutants exhibited altered hormone production and changes in processes controlled by hormones in the female, including follicle development, uterine morphology, and ovulation. Granulosa cells also participate in steroid production in the ovary and could be affected in the mutants. However, not all sterile PDGF target genes are expressed in granulosa cells, and 
Schmahl et al.
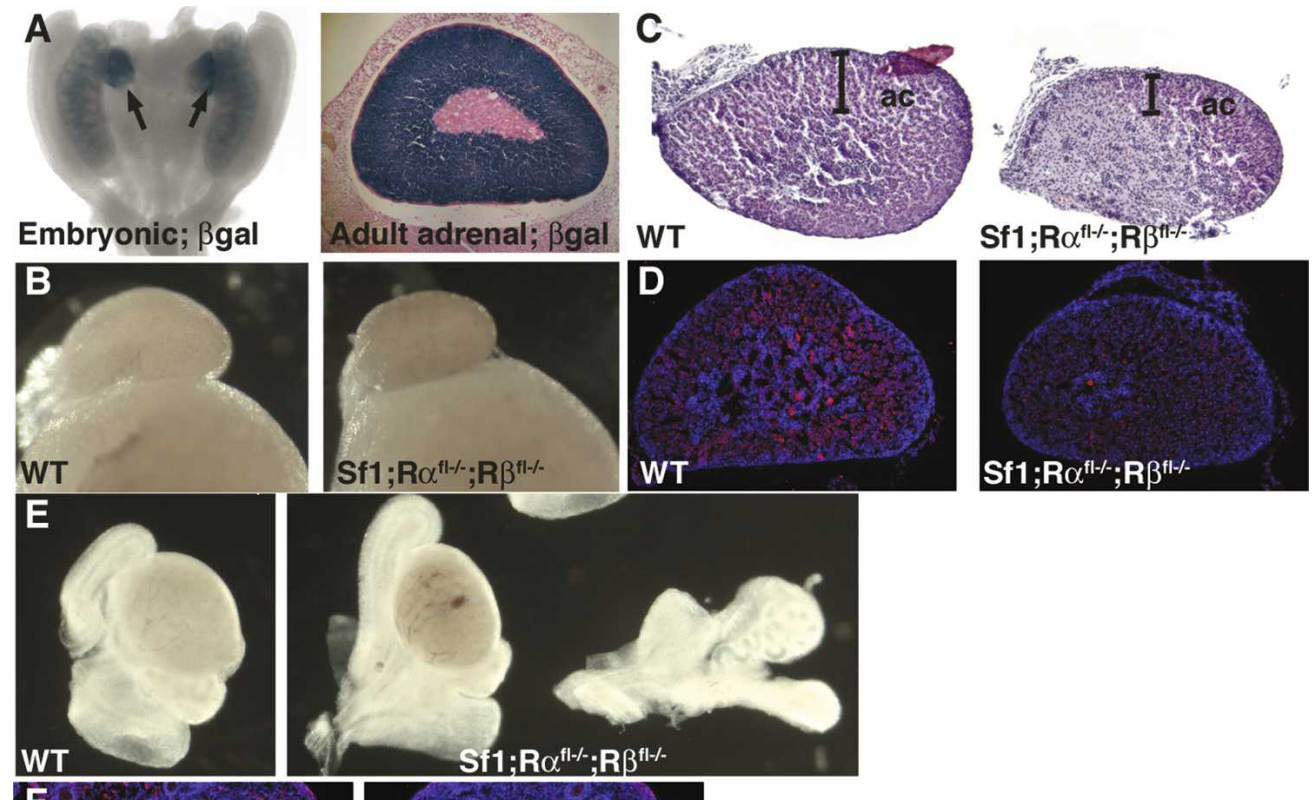

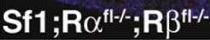
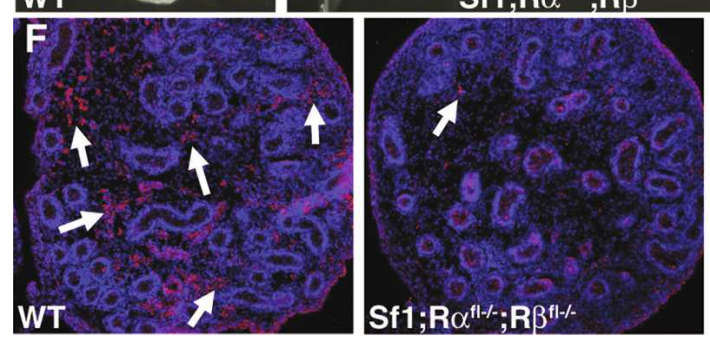

Figure 6. Conditional knockout of both $P d g f r \alpha$ and $P d g f r \beta$ in steroidogenic cells leads to defects in the testis, ovary, and adrenal gland. (A) A ROSA26R Cre reporter indicates Sf1-Cre expression in both the embryonic (arrows) and adult adrenal gland. (B) E18.5 mice with conditional deletion of both $P d g f r \alpha$ and $P d g f r \beta\left(S f 1-C r e ; P d g f r \alpha^{f l-/-} ; P d g f r \beta^{f l-l-}\right)$ have small adrenal glands. $(C, D)$ The adrenal cortex (ac, brackets) is reduced $(C)$, and steroidogenic cells are reduced in this region, as detected with an antibody against CYP11a1 $(D$, red). $(E, F)$ The testes of Sf1-Cre;Pdgfra ${ }^{f l-/} ; P d g f r \beta^{f 1-/-}$ mice are small and often hemorrhagic $(E)$, and labeling with CYP11a1 antibody indicates a reduction of steroid-producing cells ( $F$, red; examples indicated by arrows).

these cells do not express PDGF receptors during early follicle development (Sleer and Taylor 2007). Additionally, follicles are able to develop through antral stages in the sterile mutants of these targets; thus granulosa cells are not likely to be directly controlled by these genes. As the global knockouts of the PDGF receptors are lethal before follicle development in the ovary, PDGF was not previously known to be required in ovarian processes. However, using conditional mutations of the PDGF receptors, we showed that the PDGF pathway has a role in theca cells in the ovary.

The steroid-producing cell in the testis, ovary, and adrenal gland are known to be closely associated with the vasculature of these organs. In the testis, adult Leydig cells are located proximal to blood vessels and are even thought to be derived from VSMCs (Davidoff et al. 2004). In the ovary, theca cell layers are highly vascularized, and it is known that vascular remodeling in these layers is a critical component of follicle development. Defects in steroidogenic cells in the testis and ovary are often associated with changes in vascular patterning (Brennan et al. 2003; Jeays-Ward et al. 2003), suggesting that these structures may be coregulated. Interestingly, mutations of PDGF target genes that reduced steroidproducing cells also reduced VSMCs in the gonads, suggesting that these genes jointly control the development of two cell types in both the testis and ovary. PDGF signaling has well-established roles in the development of vascular-associated mesenchymal cells in many organs, including VSMCs, pericytes, and mesangial cells. This pathway is known to control migration, proliferation, and differentiation in these cell types, and thus it is possible that PDGF controls the vascular-associated steroidogenic cells in a similar manner.

Pdgfro is expressed very early in Leydig cell differentiation and may even label the Leydig stem cell population (Ge et al. 2006). Additionally, PDGF ligands can induce steroidogenesis in both Leydig and theca cell precursors in culture (Gnessi et al. 1997; Taylor 2000), suggesting that this pathway could act in the early differentiation of this cell type. This pathway may also control proliferation in these populations (Gnessi et al. 2000). Interestingly, we found that PDGF target genes in the ovary do not appear to be required for proliferation or recruitment of the theca layer to the follicle. Instead, these genes may function at later stages of differentia- 
tion and be necessary for the acquisition of steroidogenesis or the normal expression patterns of steroidogenic enzymes. In fact, the mutation of one PDGF target, Tiparp, does not lead to the loss of steroidogenesis, but instead leads to changes in the balance of steroidogenic enzymes, resulting in the expression of the androgenic enzyme $H s d 17 b 3$ in the ovary. This enzyme is normally suppressed in theca cells, suggesting that Tiparp could be part of this suppression mechanism. Interestingly, the loss of one copy of Tiparp rescues male fertility in Plekha1 ${ }^{-/}$; Tiparp $^{+/-}$mice, indicating that multiple PDGF target genes could be acting in the same molecular pathways in steroidogenic cells (see Supplemental Fig. 6 for schematic).

The steroidogenic cells of the testis, ovary, and adrenal gland are thought to share a common progenitor population in development (Hatano et al. 1996). These progenitors are first seen as an SF1-positive population found along the embryonic urogenital ridge and separate into two groups that populate either the gonad or the adrenal gland. In fact, fetal Leydig cells have been theorized to have evolved from modified adrenocortical cells (O'Shaughnessy et al. 2006), as the steroidogenic enzymes of these populations are so similar. The three different steroidogenic cell types in the testis, ovary, and adrenal are all under endocrine control from the pituitary. However, using conditional deletion of the PDGF receptors, we showed that this growth factor pathway is required for the normal function and development of these three different populations, suggesting that there may be a common pathway in the control of these cells beyond the endocrine mechanism. Interestingly, the overall expression pattern of the PDGF ligands and receptors in the gonads suggests a directional signal from the testis cords and follicles to the steroidogenic cells. This is consistent with the epithelial to mesenchymal signaling mediated by PDGF in other systems and suggests that PDGF signaling may be a conserved mechanism in the local control of steroidogenic lineages.

\section{Materials and methods}

\section{Genotyping}

Mutants of PDGF target genes were derived via insertion of the gene trap array vector (ROSAFARY), as described by Chen et al. (2004). The mutant mice are denoted as Sgpl1 ${ }^{\text {Gt(ROSA)78Sor }}$

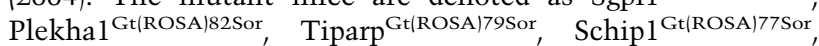
and 2610005L07Rik'Gt(ROSA)73Sor (BC058969) and are available' from the Jackson laboratories. SF1-Cre mice were a generous gift from Keith Parker (Bingham et al. 2006). The conditional Pdgfro ${ }^{f 1-/-}$ allele has been previously described (Tallquist and Soriano 2003). The conditional $P d g f r \beta^{f l}$ allele was constructed using PGKneoF2L2DTA (Hoch and Soriano 2006) by introducing loxP sites at a BstEII and a HpaI site $\sim 500$ base pairs (bp) upstream of and 2,100 bp downstream from the exons encoding the first and second immunoglobulin domain, respectively. Following homologous recombination in AK7 (129S4) embryonic stem cells, germline chimeras were derived by blastocyst injections, and the FRT-flanked PGKneo cassette was removed by crossing with ROSA26FlpeR mice (Farley et al. 2000). Muta- tions were bred on a $129 \mathrm{~S} 4 / \mathrm{S} 4$ or a mixed 129S4/C57BL/6129 background and maintained on a 13-h on light cycle. Genotypes were determined using PCR analysis of tail biopsies, using the primers listed in Supplemental Table 2. As the region containing $B C 058969$ is duplicated in the genome, Southern blots were used to determine the genotype of this mutant.

Fertility was assayed on at least two mice of each sex for all mutant lines by setting up adult (6-wk-old) mutant mice with control mice of the opposite sex for 3 mo. Mating was monitored daily for 2 wk by checking females for vaginal plugs. Additional mice were tested in lines that demonstrated fertility defects to determine the penetrance of the phenotype.

\section{Histology, staining, and immunofluorescence}

Tissue was dissected from mice at the indicated age, fixed in either 4\% paraformaldehyde or Bouin's fixative (Sigma), rinsed in PBS, dehydrated in increasing concentrations of ethanol, and cleared with Histo-Clear (National Diagnostics). To visualize testis and ovarian structures, tissues were embedded in paraffin, sectioned, and stained with Mayer's hematoxylin and eosin Y. For immunofluorescence, tissue was fixed in paraformaldehyde, put through increasing concentrations of sucrose, embedded in Tissue-Tek (Sakura, Inc.), and sectioned at 10-12 $\mu \mathrm{m}$. Sections were blocked in $10 \%$ goat serum, $0.1 \%$ Triton in PBS and incubated overnight in the indicated primary antibody. Primary antibodies were used against CYP11a1 (1:200; Chemicon, AB1294), INSL3 (1:100; Phoenix Pharmaceuticals, G-035-43), CSPG4 (1:200; Chemicon, AB5320), Desmin (1:250; DAKO clone D33), PH3 (1:300; Millipore, 06-570), and 5-Bromo-2-deoxy-uridine (BrdU) (Developmental Studies Hybridoma Bank at the University of Iowa, G3G4). An antigen retrieval step using a $2 \mathrm{~N} \mathrm{HCL}$ wash was used to detect BrdU. Fluorescently tagged secondary antibodies from Jackson ImmunoResearch (1:1000) were used to visualize antibody detection. To detect apoptosis, a FragEL DNA Fragmentation Detection Kit was used (Calbiochem, QIA39). Fluorescent sections were counterstained with DAPI $(1: 10,000)$. Images were captured using a Leica DFC290 or Optronics Magnafire camera for whole mounts and histological sections and a Zeiss Observer Camera with Axiovision software for fluorescent sections. Images were processed using Adobe Photoshop software.

\section{$X$-gal staining and in situ hybridization}

$\mathrm{X}$-gal staining was done using standard protocols on heterozygous mice between 6 and 12 wk of age, and sections were counterstained with nuclear fast red. As the insertion into BC058969 has low $\beta$-gal activity (Schmahl et al. 2007), the expression patterns of this gene were detected using sectioned and wholemount in situ hybridization using standard techniques. The probe for this gene was derived from cloned 3' RACE products derived as described (Chen et al. 2004). Probes for Pdgfra, $P d g f r b, P d g f a, P d g f b$, and $P d g f c$ were derived from cDNA using standard protocols.

\section{Hormone levels}

Circulating hormone levels were determined by harvesting blood using retro-orbital bleed. Males were harvested at the indicated ages ( 6 and $10 \mathrm{wk}$ of age), at 10-11 a.m. to reduce variability due to time of day. In females, the estrus cycle was monitored using vaginal lavage, and blood was taken between 6 and $10 \mathrm{wk}$ of age from mice in early estrus phase at 6-7 p.m. Many infertile mutants had greatly elongated estrus cycles, and some did not enter a clear estrus phase during the 3-wk moni- 
toring period. In these mice, blood was taken at the stage closest to estrus that could be achieved, generally late proestrus. Serum was extracted via centrifugation in serum separator tubes and hormones measured using a measured using a radioimmunoassay (RIA) from Diagnostic Systems Laboratories, including testosterone (DSL-4000), estradiol (DSL-43100), LH (DSL-4600), and FSH (DSL-4700). To determine testosterone levels in the testis, this organ was homogenized and extracted using two changes of $5 \mathrm{~mL}$ of diethyl ether. These extractions were allowed to evaporate and dissolved in PBS, and testosterone levels were measured as above. Between five and 10 samples were taken from each genotype and sex unless otherwise indicated. Sgpl1 $1^{-/-}$and Plekha1 ${ }^{-/-} ;$Pdgfra ${ }^{+/-}$mice have reduced viability and thus only one to three samples were measured from these lines. The standard error of the mean (SEM) is shown for each genotype as an error bar.

\section{RNA isolation and real-time PCR}

Testes and ovaries of the appropriate genotype were homogenized in TRIZOL reagent (GIBCO-BRL), and total RNA was isolated according to manufacturer. Random-primed cDNA was synthesized using iScript (Bio-Rad S60), and real-time PCR was performed using IQ Syber Green Mix (Bio-Rad 170-8880) and the primers listed in Supplemental Table 3. Real-time PCR was preformed and analyzed using the iQ5 Optical System RealTime PCR machine and software. A melting curve and dilution series were done on each primer pair to determine efficiency and rule out secondary reaction products and primer dimer formation. Real-time PCR was then preformed over 40 cycles at $60^{\circ} \mathrm{C}$. RNA concentrations were equalized before cDNA synthesis, and each sample was also normalized using a reference gene (Ubc). The Pfaffl normalization method was used to take into account different efficiencies of each primer set. For each genotype and sex, two to four samples were measured, with each done in triplicate. Expression is shown relative to a wild-type sample, and error bars indicate SEM.

\section{Acknowledgments}

We thank Marc Grenley for dedicated assistance with many procedures; Philip Corrin and Alan Wong for excellent technical support; Susan Parkhurst, Marc Van Gilst, and our laboratory colleagues for critical reading of the manuscript; and Keith Parker for the SF1-Cre mice. This work was supported by a post-doctoral fellowship from the National Institute of General Medical Sciences (GM071158) to J.S., a grant HD24875 from the National Institute of Child Health and Human Development to P.S., and a gift from the Merck Research Laboratories to P.S.

\section{References}

Andrae, J., Gallini, R., and Betsholtz, C. 2008. Role of plateletderived growth factors in physiology and medicine. Genes \& Dev. 22: 1276-1312.

Balvers, M., Spiess, A.N., Domagalski, R., Hunt, N., Kilic, E., Mukhopadhyay, A.K., Hanks, E., Charlton, H.M., and Ivell, R. 1998. Relaxin-like factor expression as a marker of differentiation in the mouse testis and ovary. Endocrinology 139: 2960-2970.

Basciani, S., Mariani, S., Arizzi, M., Ulisse, S., Rucci, N., Jannini, E.A., Della Rocca, C., Manicone, A., Carani, C., Spera, G., et al. 2002. Expression of platelet-derived growth factor-A (PDGF-A), PDGF-B, and PDGF receptor- $\alpha$ and $-\beta$ during human testicular development and disease. J. Clin. En- docrinol. Metab. 87: 2310-2319.

Bingham, N.C., Verma-Kurvari, S., Parada, L.F., and Parker, K.L. 2006. Development of a steroidogenic factor $1 /$ Cre transgenic mouse line. Genesis 44: 419-424.

Brennan, J. and Capel, B. 2004. One tissue, two fates: Molecular genetic events that underlie testis versus ovary development. Nat. Rev. Genet. 5: 509-521.

Brennan, J., Tilmann, C., and Capel, B. 2003. Pdgfr- $\alpha$ mediates testis cord organization and fetal Leydig cell development in the XY gonad. Genes \& Dev. 17: 800-810.

Chen, W.V., Delrow, J., Corrin, P.D., Frazier, J.P., and Soriano, P. 2004. Identification and validation of PDGF transcriptional targets by microarray-coupled gene-trap mutagenesis. Nat. Genet. 36: 304-312.

Clark, A.M., Garland, K.K., and Russell, L.D. 2000. Desert hedgehog (Dhh) gene is required in the mouse testis for formation of adult-type Leydig cells and normal development of peritubular cells and seminiferous tubules. Biol. Reprod. 63: $1825-1838$.

Couse, J.F., Yates, M.M., Rodriguez, K.F., Johnson, J.A., Poirier, D., and Korach, K.S. 2006. The intraovarian actions of estrogen receptor- $\alpha$ are necessary to repress the formation of morphological and functional Leydig-like cells in the female gonad. Endocrinology 147: 3666-3678.

Davidoff, M.S., Middendorff, R., Enikolopov, G., Riethmacher, D., Holstein, A.F., and Muller, D. 2004. Progenitor cells of the testosterone-producing Leydig cells revealed. J. Cell Biol. 167: 935-944.

DiNitto, J.P. and Lambright, D.G. 2006. Membrane and juxtamembrane targeting by $\mathrm{PH}$ and PTB domains. Biochim. Biophys. Acta 1761: 850-867.

Dong, J., Albertini, D.F., Nishimori, K., Kumar, T.R., Lu, N., and Matzuk, M.M. 1996. Growth differentiation factor-9 is required during early ovarian folliculogenesis. Nature 383: 531-535.

Farley, F.W., Soriano, P., Steffen, L.S., and Dymecki, S.M. 2000. Widespread recombinase expression using FLPeR (flipper) mice. Genesis 28: 106-110.

Fisher, C.R., Graves, K.H., Parlow, A.F., and Simpson, E.R. 1998. Characterization of mice deficient in aromatase (ArKO) because of targeted disruption of the cyp19 gene. Proc. Natl. Acad. Sci. 95: 6965-6970.

Ge, R.S., Dong, Q., Sottas, C.M., Papadopoulos, V., Zirkin, B.R., and Hardy, M.P. 2006. In search of rat stem Leydig cells: Identification, isolation, and lineage-specific development Proc. Nat1. Acad. Sci. 103: 2719-2724.

Gelety, T.J. and Magoffin, D.A. 1997. Ontogeny of steroidogenic enzyme gene expression in ovarian theca-interstitial cells in the rat: Regulation by a paracrine theca-differentiating factor prior to achieving luteinizing hormone responsiveness. Biol. Reprod. 56: 938-945.

Gnessi, L., Emidi, A., Jannini, E.A., Carosa, E., Maroder, M. Arizzi, M., Ulisse, S., and Spera, G. 1995. Testicular development involves the spatiotemporal control of PDGFs and PDGF receptors gene expression and action. J. Cell Biol. 131: 1105-1121.

Gnessi, L., Fabbri, A., and Spera, G. 1997. Gonadal peptides as mediators of development and functional control of the testis: An integrated system with hormones and local environment. Endocr. Rev. 18: 541-609.

Gnessi, L., Basciani, S., Mariani, S., Arizzi, M., Spera, G., Wang, C., Bondjers, C., Karlsson, L., and Betsholtz, C. 2000. Leydig cell loss and spermatogenic arrest in platelet-derived growth factor (PDGF)-A-deficient mice. J. Cell Biol. 149: 1019-1026.

Goutebroze, L., Brault, E., Muchardt, C., Camonis, J., and Thomas, G. 2000. Cloning and characterization of SCHIP-1, 
a novel protein interacting specifically with spliced isoforms and naturally occurring mutant NF2 proteins. Mol. Cell. Biol. 20: 1699-1712.

Habert, R., Lejeune, H., and Saez, J.M. 2001. Origin, differentiation and regulation of fetal and adult Leydig cells. Mol. Cell. Endocrinol. 179: 47-74.

Hasegawa, T., Zhao, L., Caron, K.M., Majdic, G., Suzuki, T., Shizawa, S., Sasano, H., and Parker, K.L. 2000. Developmental roles of the steroidogenic acute regulatory protein (StAR) as revealed by StAR knockout mice. Mol. Endocrinol. 14: 1462-1471.

Hatano, O., Takakusu, A., Nomura, M., and Morohashi, K. 1996. Identical origin of adrenal cortex and gonad revealed by expression profiles of Ad4BP/SF-1. Genes Cells 1: 663-671.

Hoch, R. and Soriano, P. 2003. PDGF roles in animal development. Development 130: 4769-4784.

Hoch, R.V. and Soriano, P. 2006. Context-specific requirements for Fgfr1 signaling through Frs2 and Frs3 during mouse development. Development 133: 663-673.

Jeays-Ward, K., Hoyle, C., Brennan, J., Dandonneau, M., Alldus, G., Capel, B., and Swain, A. 2003. Endothelial and steroidogenic cell migration are regulated by WNT4 in the developing mammalian gonad. Development 130: 3663-3670.

Klinghoffer, R.A., Mueting-Nelsen, P.F., Faerman, A., Shani, M., and Soriano, P. 2001. The two PDGF receptors maintain conserved signaling in vivo despite divergent embryological functions. Mol. Cell 7: 343-354.

Knight, P.G. and Glister, C. 2006. TGF- $\beta$ superfamily members and ovarian follicle development. Reproduction 132: 191206.

Kotsuji, F. and Tominaga, T. 1994. The role of granulosa and theca cell interactions in ovarian structure and function. $\mathrm{Mi}$ crosc. Res. Tech. 27: 97-107.

Loveland, K.L., Zlatic, K., Stein-Oakley, A., Risbridger, G., and deKretser, D.M. 1995. Platelet-derived growth factor ligand and receptor subunit mRNA in the Sertoli and Leydig cells of the rat testis. Mol. Cell. Endocrinol. 108: 155-159.

Ma, Q., Baldwin, K.T., Renzelli, A.J., McDaniel, A., and Dong, L. 2001. TCDD-inducible poly(ADP-ribose) polymerase: A novel response to 2,3,7,8-tetrachlorodibenzo-p-dioxin. Biochem. Biophys. Res. Commun. 289: 499-506.

Magoffin, D.A. 2005. Ovarian theca cell. Int. J. Biochem. Cell Biol. 37: 1344-1349.

O'Shaughnessy, P.J., Baker, P.J., and Johnston, H. 2006. The foetal Leydig cell-Differentiation, function and regulation. Int. J. Androl. 29: 90-95.

Saez, J.M. 1994. Leydig cells: Endocrine, paracrine, and autocrine regulation. Endocr. Rev. 15: 574-626.

Schmahl, J., Raymond, C.S., and Soriano, P. 2007. PDGF signaling specificity is mediated through multiple immediate early genes. Nat. Genet. 39: 52-60.

Sleer, L.S. and Taylor, C.C. 2007. Cell-type localization of platelet-derived growth factors and receptors in the postnatal rat ovary and follicle. Biol. Reprod. 76: 379-390.

Soriano, P. 1994. Abnormal kidney development and hematological disorders in PDGF $\beta$-receptor mutant mice. Genes \& Dev. 8: 1888-1896.

Soriano, P. 1997. The PDGF $\alpha$ receptor is required for neural crest cell development and for normal patterning of the somites. Development 124: 2691-2700.

Tallquist, M.D. and Soriano, P. 2003. Cell autonomous requirement for PDGFR $\alpha$ in populations of cranial and cardiac neural crest cells. Development 130: 507-518.

Taylor, C.C. 2000. Platelet-derived growth factor activates porcine thecal cell phosphatidylinositol-3-kinase-Akt/PKB and ras-extracellular signal-regulated kinase-1/2 kinase signaling pathways via the platelet-derived growth factor- $\beta$ receptor. Endocrinology 141: 1545-1553.

Toda, K., Takeda, K., Okada, T., Akira, S., Saibara, T., Kaname, T., Yamamura, K., Onishi, S., and Shizuta, Y. 2001. Targeted disruption of the aromatase P450 gene (Cyp19) in mice and their ovarian and uterine responses to $17 \beta$-oestradiol. J. Endocrinol. 170: 99-111.

Van Veldhoven, P.P. 2000. Sphingosine-1-phosphate lyase. Methods Enzymol. 311: 244-254.

Yoon, S.J., Kim, K.H., Chung, H.M., Choi, D.H., Lee, W.S., Cha, K.Y., and Lee, K.A. 2006. Gene expression profiling of early follicular development in primordial, primary, and secondary follicles. Fertil. Steril. 85: 193-203. 


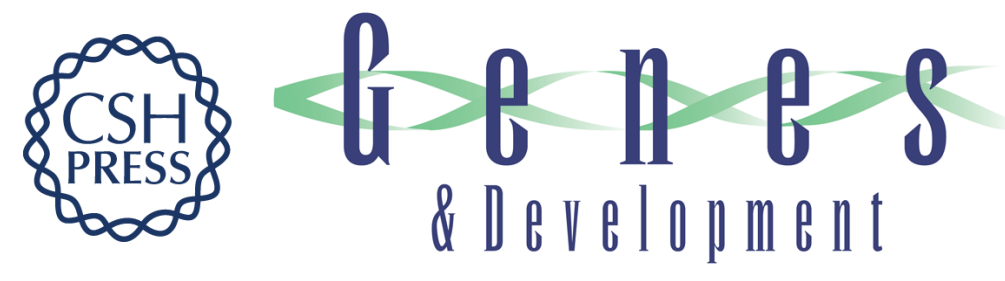

\section{The PDGF signaling pathway controls multiple steroid-producing lineages}

Jennifer Schmahl, Kamran Rizzolo and Philippe Soriano

Genes Dev. 2008, 22:

Access the most recent version at doi:10.1101/gad.1723908

Supplemental
Material http://genesdev.cshlp.org/content/suppl/2008/11/18/22.23.3255.DC1

References This article cites 43 articles, 16 of which can be accessed free at: http://genesdev.cshlp.org/content/22/23/3255.full.html\#ref-list-1

License

Email Alerting Receive free email alerts when new articles cite this article - sign up in the box at the top Service right corner of the article or click here.

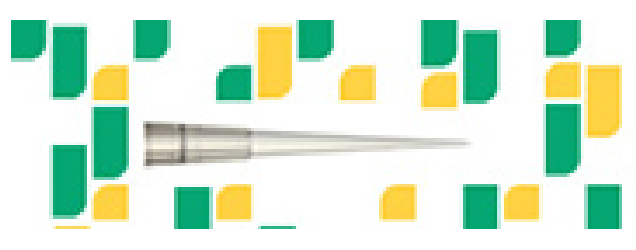

Focused on your science. 